\title{
Factors Associated with One-year Mortality in Patients with Acute Pulmonary Embolism
}

\author{
Diana Opincariu ${ }^{1}$, András Mester ${ }^{1}$, Mihaela Rațiu ${ }^{2}$, Nora Rat ${ }^{2}$, Lehel Bordi ${ }^{1}$, Roxana Hodas ${ }^{2}$, \\ Mirabela Morariu², Beáta Jakó ${ }^{2}$, Camelia Tănăsuc ${ }^{1}$, Zsuzsanna Suciu² \\ ${ }^{1}$ Center of Advanced Research in Multimodality Cardiac Imaging, Cardio Med Medical Center, Tîrgu Mureș, Romania \\ ${ }^{2}$ Clinic of Cardiology, University of Medicine and Pharmacy, Tîrgu Mureș, Romania
}

\section{ABSTRACT}

Introduction: Pulmonary embolism (PE) is the most common cause of vascular death after myocardial infarction and stroke, being associated with high mortality and morbidity rates. The aim of this study was to assess the factors related to 1-year mortality in patients with acute pulmonary embolism who survived the acute event. Material and methods: In total, 104 patients who had survived the acute episode of pulmonary embolism and underwent a onemonth follow-up after the acute event were included in the study. The patients were divided into two groups: Group 1 - patients who had survived at one year after being diagnosed with acute PE $(80.76 \%, \mathrm{n}=84)$, and Group 2 - patients who had died after one year $(19.23 \%, \mathrm{n}=$ 20). Results: There were no differences between the 2 groups in relation to gender $(p=0.3)$, or cardiovascular risk factors (diabetes: $\mathrm{p}=0.5$, smoking: $\mathrm{p}=0.3$, hypertension: $\mathrm{p}=1$, hypercholesterolemia: $\mathrm{p}=0.5$, hypertriglyceridemia: $\mathrm{p}=0.4)$. Patients who had deceased were significantly older $(73.35 \pm 9.37$ years vs. $66.36 \pm 11.17$ years, $\mathrm{p}=0.005)$ and had a higher weight compared to the survivors $(85.8 \pm 21.09 \mathrm{~kg}$ vs. $75.89 \pm 22.69 \mathrm{~kg}, \mathrm{p}=0.03)$. Left ventricular ejection fraction, measured by cardiac ultrasound, was significantly lower in the deceased group compared to survivors ( $45.63 \pm 8.9 \%$ vs. $52.86 \pm 6.8 \%, \mathrm{p}=0.03)$. Multivariate analysis identified the hemodynamic instability (OR $=3.17, \mathrm{p}=0.007)$, the presence of left $\mathrm{QRS}$ axis deviation $(\mathrm{OR}=4.81, \mathrm{p}=0.001)$, associated pulmonary pathologies $(\mathrm{OR}=3.2, \mathrm{p}=0.02)$ as well as the presence of chronic kidney disease $(\mathrm{OR}=5, \mathrm{p}=0.04)$ as the most powerful predictors of death at 1 year in patients with acute PE surviving the acute event. Conclusions: Factors associated with a higher mortality rate at 1 year in patients who had survived at 1 month following an acute pulmonary embolism episode included: older age, higher body weight, presence of associated pulmonary pathologies, chronic kidney disease, left axis deviation, low left ventricular ejection fraction, hemodynamic instability requiring inotropic support, cardiogenic shock at presentation or cardiac arrest during the acute phase.

Keywords: pulmonary embolism, thromboembolism, cardiovascular mortality

\section{ARTICLE HISTORY}

Received: 13 March, 2016

Accepted: 19 May, 2016

\section{CORRESPONDENCE}

\section{András Mester}

Str. 22 Decembrie 1989 nr. 76

540124 Tîrgu Mureș, Romania

Tel:+40 265217333

E-mail: andras.mester@yahoo.com

Diana Opincariu: Str. 22 Decembrie 1989 nr. 76, 540124 Tîrgu Mureș, Romania. Tel: +40 265 217 333. E-mail: diana.opincariu@yahoo.ro Mihaela Rațiu: Str. Gheorghe Marinescu nr. 38, 540139 Tîrgu Mureș, Romania. Tel: +40 265215 551. E-mail: mihnea.dobre91@yahoo.com Nora Rat: Str. Gheorghe Marinescu nr. 38, 540139 Tîrgu Mureș, Romania. Tel: +40 265215 551. E-mail: ratnora@gmail.com Lehel Bordi: Str. 22 Decembrie 1989 nr. 76, 540124 Tîrgu Mureș, Romania. Tel: +40 265217 333, E-mail: bordi_lehel@yahoo.com Roxana Hodas: Str. Gheorghe Marinescu nr. 38, 540139 Tîrgu Mureș, Romania. Tel: +40 265215 551. E-mail: roxana.hodas@yahoo.ro Mirabela Morariu: Str. Gheorghe Marinescu nr. 38, 540139 Tîrgu Mureș, Romania. Tel: +40 265 215 551. E-mail: mirabela.morariu@yahoo.com Beáta Jakó: Str. Gheorghe Marinescu nr. 38, 540139 Tîrgu Mureș, Romania. Tel: +40 265215 551. E-mail: beatajako@gmail.com Camelia Tănăsuc: Str. 22 Decembrie 1989 nr. 76, 540124 Tîrgu Mureș, Romania. Tel: +40 265217 333. E-mail: cameliatanasuc@gmial.com Zsuzsanna Suciu: Str. Gheorghe Marinescu nr. 38, 540139 Tîrgu Mureș, Romania. Tel: +40 265215 551. E-mail: szoke_zsuzsanna@yahoo.com 


\section{INTRODUCTION}

Pulmonary embolism (PE) is the most common cause of vascular death after myocardial infarction and stroke, being associated with high mortality and morbidity rates., ${ }^{1,2}$ The incidence of both idiopathic and secondary forms of PE increases exponentially with age, with an average annual incidence of approximately 108 per 100,000 persons. 3,4

The important consequences of acute $\mathrm{PE}$ are related to the alteration of the hemodynamic status of the patients, and is evident when more than $30-40 \%$ of the pulmonary arterial bed is occluded by thromboembolism. ${ }^{5,6}$ This occlusion may be life-threating in the acute phase, but the right ventricular failure is potentially reversible. Therefore it is imperative to establish the correct diagnosis at an early stage, when treatment is highly effective.?

The diagnosis of PE in emergency settings is based mainly on the assessment of the patient's clinical status.

The clinical evaluation ranks patients into several probability categories. In Europe, the most frequently used clinical PE prediction scores are the Wells and Geneva scores. The revised Geneva score is a simple, standardized score based completely on clinical variables. The Wells score consists of seven clinical criteria. Both scores classify patients into low, moderate or high clinical probability categories. ${ }^{8,9}$

Right ventricular dysfunction, including acute dilation, assessed by cardiac ultrasound is found in at least $25 \%$ of patients with PE. Echocardiographic criteria, used for the diagnosis of $\mathrm{PE}$, are usually based on the velocity of the tricuspid regurgitation jet and right ventricular measurements. Echocardiography provides information on the differential diagnosis of cardiogenic shock caused by the $\mathrm{PE}$, by detecting acute valvular dysfunction, cardiac tamponade or myocardial infarction. ${ }^{10-13}$

Electrocardiography (ECG) can show several abnormalities, mostly based on right ventricular (RV) overload, seen as right ventricular dysfunction, but, on their own, none of these different ECG signs are specific enough to confirm the diagnosis of $\mathrm{PE}$. The presence of right bundle branch block and $\mathrm{S}_{103 \mathrm{~T}} 3$ patterns in acute $\mathrm{PE}$ events appears to be associated with a poorer outcome and RV overload. ${ }^{14,15}$

Currently, plasma D-dimer is not considered a useful biomarker for confirming PE. Normal values of plasma D-dimer can exclude PE in patients with a low or moderate clinical probability. In most countries, computed tomography (CT) angiography, which allows visualization of the pulmonary arteries up to at least the segmental level, has become the method of choice for diagnosing acute $\mathrm{PE}$ in patients with high clinical probability or low/moderate probability but elevated D-dimer levels. ${ }^{16-18}$

Various biomarkers have been considered for diagnosing risk categories and prognosis in PE patients. Some studies showed that the $\mathrm{N}$-terminal brain natriuretic peptide (NTproBNP), a biomarker characterizing right ventricular dysfunction, is an indicator of short-term prognosis in PE patients. At the same time, this is a very useful biomarker for monitorization of the in-hospital evolution and the assessment of short-term prognosis associated with the disease. ${ }^{19,20}$ Interestingly, decreased serum levels of total cholesterol and triglycerides have been found to be associated with increased short-term mortality in $\mathrm{PE}$ patients, and measurements of cholesterol levels within 24 hours of hospitalization may be valuable in predicting short-term outcomes. ${ }^{21}$

The aim of the present study was to assess the factors associated with one-year mortality in patients with acute pulmonary embolism who survived an acute event.

\section{MATERIALS AND METHOD}

In total, 104 patients who had survived the acute episode of $\mathrm{PE}$ and underwent a one-month follow-up at the Cardio Med Medical Center from Tîrgu Mures, Romania, during the period January 2014 - May 2015 were included in the study. Groups were defined by the status of the patients at one year following the event. Group 1: patients who were alive at the one-year follow-up. Group 2: patients who died during the first year before follow-up.

Baseline characteristics, patient demographics, laboratory results, cardiovascular risk factors, associated diseases, as well as the imaging results (CT pulmonary angiography, echocardiography) were retrospectively collected from the patients' medical files.

The primary end-point of the study was the all-cause mortality at one year in survivors of acute pulmonary embolism.

Statistical analysis was performed using Graph Pad Prism version 6.0 statistical software. Continuous variables were expressed as mean (SD) and categorical variables as frequencies and percentages.

Comparisons between the two groups were performed using the $\mathrm{Chi}^{2}$ test with Yates correction of Fisher's exact test when appropriate, for qualitative data. For quantitative variables, the comparison between the groups was made using the two-tailed Student t-test or the twotailed Mann-Whitney test, when appropriate. 
The relative performance of each test was evaluated with the 95\% confidence interval (CI). The level of significance was set at $\mathrm{p}=0.05$.

Multivariate analysis was performed to identify the most significant predictors of death at one year following an acute PE episode in patients who survived the acute event.

All patients included in the study gave informed consent, and the study was approved by the Ethics Committee of the Cardio Med Clinic. All the study procedures were performed in agreement with the principles stipulated in the Declaration of Helsinki.

\section{RESULTS}

There were $84(80.76 \%)$ patients in Group 1 and 20 $(19.23 \%$,$) in Group 2. There were no differences between$ the two groups in relation to gender $(\mathrm{p}=0.3)$, or cardiovascular risk factors (diabetes: $\mathrm{p}=0.5$, smoking: $\mathrm{p}=0.3$, hypertension: $\mathrm{p}=1$, hypercholesterolemia: $\mathrm{p}=0.5$, hypertriglyceridemia: $\mathrm{p}=0.4$ ).

However, there were significant differences between the groups with respect to age and body weight. Patients who had died were significantly older, $73.35 \pm 9.37$ years vs. $66.36 \pm 11.17$ years $(\mathrm{p}=0.005)$ and were of greater weight compared to the survivors, $85.8 \pm 21.09 \mathrm{~kg}$ vs. $75.89 \pm 22.69 \mathrm{~kg}$. $(\mathrm{p}=0.03)$. The baseline characteristics,

TABLE 1. Baseline characteristics of the study population

\begin{tabular}{lccc}
\hline Characteristic & $\begin{array}{c}\text { Deceased } \\
\mathbf{n}=\mathbf{2 0}\end{array}$ & $\begin{array}{c}\text { Survivors } \\
\mathbf{n}=\mathbf{8 4}\end{array}$ & p value \\
\hline Age (years) & $73.35 \pm 9.37$ & $66.36 \pm 11.17$ & 0.005 \\
Weight & $85.8 \pm 21.09$ & $75.89 \pm 22.69$ & 0.03 \\
Male gender & $11(55 \%)$ & $38(45.23 \%)$ & 0.3 \\
Arterial hypertension & $14(70 \%)$ & $57(67.95 \%)$ & 1 \\
Smoking & $0(0 \%)$ & $8(9.52 \%)$ & 0.3 \\
Diabetes & $2(10 \%)$ & $16(19.04 \%)$ & 0.5 \\
Hyper-Cholesterolemia & $3-15 \%$ & $21(25 \%)$ & 0.5 \\
Hyper-triglyceridemia & $1-5 \%$ & $12(14.28 \%)$ & 0.4 \\
Supraventricular arrythmias* & $5-25 \%$ & $18(21.42 \%)$ & 0.7 \\
Obesity & $4-20 \%$ & $26(30.95 \%)$ & 0.4 \\
Pulmonary pathologies** & $10-50 \%$ & $20(23.8 \%)$ & 0.02 \\
Diabetes & $2-10 \%$ & $16(19.04 \%)$ & 0.5 \\
Chronic kidney disease & $4-20 \%$ & $4(4.76 \%)$ & 0.04 \\
PAD*** & $1-5 \%$ & $3(3.57 \%)$ & 0.6 \\
Stroke/Neurological disorders & $4-20 \%$ & $22(26.19 \%)$ & 0.8 \\
\hline
\end{tabular}

* include atrial fibrillation, atrial flutter, supraventricular tachycardias;

** include chronic obstructive pulmonary disease, asthma, pneumonia, pleural effusion, pulmonary tumors, chronic infiltrative pulmonary disorders;

*** PAD - peripheral artery disease the cardiovascular risk factors and the associated diseases are listed in Table 1 . There was a significantly higher rate of associated pulmonary pathologies, COPD, asthma, pneumonia, pleural effusion, pulmonary tumors and infiltrative lung disease $(p=0.02)$. There was also a higher rate of chronic kidney disease $(\mathrm{p}=0.04)$ in the case of patients who died, compared to survivors.

$19.04 \%$ of patients who had survived had a history of recurrent pulmonary embolism compared to only $10 \%$ of the deceased. However, this difference was not statistically significant $(\mathrm{p}=0.3)$.

The etiology of the acute pulmonary embolism episode (Table 2) did not differ significantly between the two groups. No statistically significant difference was recorded between the two groups in relation to the presence of deep venous thrombosis, neoplasms, prolonged immobilization, chronic venous insufficiency, intra-cardiac masses or oral contraceptives.

The analysis of the clinical characteristics of the two groups revealed that patients who died in the first year after the event had a higher peripheral pulse rate compared to those who survived, $102.7 \pm 19.03 \mathrm{bpm}$ vs. $89.57 \pm 18.53$ $\mathrm{bpm}, * * *(\mathrm{p}=0.003)$. There were no significant differences between the groups with respect to mean systolic $-120 \pm 24.72 \mathrm{mmHg}$ vs. $124.9 \pm 23.9 \mathrm{mmHg}(\mathrm{p}=0.4)$, or diastolic arterial pressure $-68.7 \pm 17.1 \mathrm{mmHg}$ vs. $73.81 \pm$ $14.14 \mathrm{mmHg}(\mathrm{p}=0.2)$.

Hemodynamic instability, defined as cardiogenic shock requiring inotropic support or the presence of cardiac arrest during the acute phase of the $\mathrm{PE}$, was present to a significantly greater extent in patients who had died in the $1^{\text {st }}$ year after an acute PE, compared to those that had survived (Figure 1).

Laboratory test results did not show any statistically significant differences between the two groups, except the

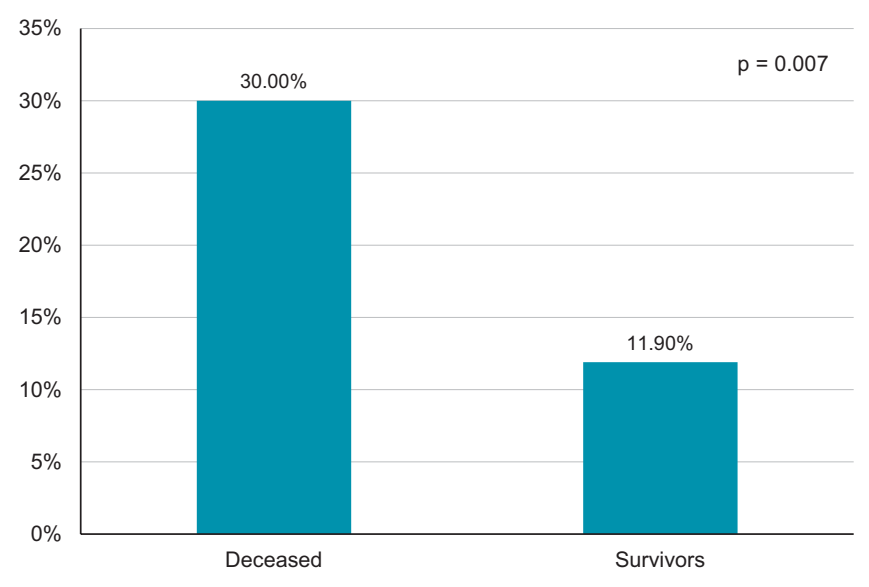

FIGURE 1. Hemodynamic instability at baseline 
TABLE 2. The etiology of acute pulmonary embolism

\begin{tabular}{|c|c|c|c|c|c|}
\hline Cause & $\begin{array}{c}\text { Deceased } \\
\mathrm{n}=20\end{array}$ & $\begin{array}{c}\text { Survivors } \\
\mathrm{n}=84\end{array}$ & $\mathrm{p}$ value & OR & $\mathrm{CI}(95 \%)$ \\
\hline Unknown & $4(20 \%)$ & $22(26.19 \%)$ & 0.5 & 0.704 & $0.21-2.3$ \\
\hline Deep Venous Thrombosis & $8(40 \%)$ & $28(29.76 \%)$ & 0.6 & 1.30 & $0.48-3.6$ \\
\hline Neoplasm & $2(10 \%)$ & $3(3.57 \%)$ & 0.2 & 3.00 & $0.46-19.29$ \\
\hline $\begin{array}{l}\text { Imobilization (due to other causes than } \\
\text { surgery or trauma) }\end{array}$ & $3(15 \%)$ & $6(7.14 \%)$ & 0.6 & 1.40 & $0.26-7.75$ \\
\hline Chronic venous insufficiency & $3(15 \%)$ & $13(15.47 \%)$ & 1 & 0.96 & $0.24-3.76$ \\
\hline Cardiac causes & $3(15 \%)$ & $7(8.33 \%)$ & 0.4 & 1.90 & $0.45-8.2$ \\
\hline Imobilzation due to surgery or trauma & $1(5 \%)$ & $4(4.76 \%)$ & 1 & 1.05 & $0.11-9.96$ \\
\hline Oral contraceptives & $0(0 \%)$ & $1(1.19 \%)$ & 1 & 1.30 & $0.053-34.59$ \\
\hline
\end{tabular}

white blood cell count, which was considerably higher in patients that had died in the $1^{\text {st }}$ year, compared to survivors $(\mathrm{p}=0.0005)$ (Table 3$)$. The serum levels of D-dimers were not significantly higher in patients who died after one year. A positive $\mathrm{D}$-dimer test, defined as a serum level of $\mathrm{D}$-dimer $>5$ micrograms $/ \mathrm{ml}$ was encountered in $65 \%$ of patients in Group 1 as compared to 53.57\% of patients in Group 2, the difference being not statistically significant $(p=0.3)$.

Electrocardiography showed the presence of a left QRS axis deviation in a significantly higher rate in patients that had deceased - 55\%, compared to survivors $-20.23 \%$ ( $\mathrm{p}$ $=0.001$ ). However, there were no differences between the two groups regarding the presence of right bundle branch block, negative $\mathrm{T}$ waves in leads $\mathrm{V} 1-\mathrm{V} 3$, or the presence of $\mathrm{S} 1 \mathrm{Q} 3 \mathrm{~T} 3$ aspect on the baseline ECG (Figure 2).
The echocardiographic examination revealed no differences between the two groups in relation to the right ventricular diameter $(p=0.9)$ or the presence of tricuspid regurgitation $(p=0.8)$. However, left ventricular ejection fraction, measured by cardiac ultrasound, was significantly lower in the deceased group, $45.63 \pm 8.9 \%$, compared to survivors, $52.86 \pm 6.8 \%(\mathrm{p}=0.03)$ (Figure 3 ).

Bilateral PE as shown by pulmonary computed tomography angiogram was significantly associated with a higher mortality at one year. Sixty per cent of patients from the deceased group had presented with a bilateral $\mathrm{PE}$, compared to $70.23 \%$ in the survivor group $(\mathrm{p}=0.4$, OR $=0.63$, CI: 0.23-1.74).

Analysis of the Geneva risk score indicated that the mean integer value was significantly lower for the survivors (6.73

TABLE 3. Laboratory test results

\begin{tabular}{lccc}
\hline Cause & $\begin{array}{c}\text { Deceased } \\
\mathbf{n}=\mathbf{2 0}\end{array}$ & $\begin{array}{c}\text { Survivors } \\
\mathbf{n}=\mathbf{8 4}\end{array}$ & p value \\
\hline CK (UI/L) & $298.8 \pm 156$ & $213.2 \pm 59.37$ & 0.6 \\
LDH (UI/L) & $301.8 \pm 120.3$ & $282.8 \pm 124.1$ & 0.4 \\
BiT (mg/dl) & $1.14 \pm 0.79$ & $0.75 \pm 0.35$ & 0.2 \\
CTnI (ng/ml) & $0.311 \pm 0.204$ & $1.31 \pm 0.412$ & 0.8 \\
NT pro BNP (pg/dl) & $8,426 \pm 3,371$ & $6,048 \pm 965.2$ & 0.5 \\
ASAT (UI/L) & $70.65 \pm 19.98$ & $62.05 \pm 12.63$ & 0.5 \\
ALAT (UI/L) & $101.6 \pm 50.08$ & $74.04 \pm 17.81$ & 0.6 \\
White cell blood count & $13,700 \pm 6,717$ & $9,689 \pm 3,662$ & 0.0005 \\
Platelet count & $231,941 \pm 95,552$ & $203,211 \pm 63,485$ & 0.2 \\
Urea (mg/dl) & $58.53 \pm 11.26$ & $60.38 \pm 10.16$ & 0.1 \\
Creatinine (mg/dl) & $1.241 \pm 0.13$ & $2.2 \pm 1.2$ & 0.2 \\
Glycemia (mg/dl) & $137.1 \pm 96.62$ & $163.3 \pm 137.3$ & 0.8 \\
Haematocrit (\%) & $38.46 \pm 5.11$ & $52.57 \pm 68.35$ & 0.3 \\
Haemoglobin (mg/dl) & $18.74 \pm 6.18$ & $19.2 \pm 2.71$ & 0.06 \\
Total Cholesterol (mg/dl) & $152.8 \pm 40.73$ & $198.5 \pm 196.1$ & 0.05 \\
Triglycerides (mg/dl) & $115 \pm 47.31$ & $149.4 \pm 129.8$ & 0.2 \\
\hline
\end{tabular}






FIGURE 2. ECG presentation at baseline

\pm 3.72 vs. $9.9 \pm 4.4, \mathrm{p}=0.009)$. Furthermore, when comparing the Geneva risk categories between the two groups, more patients classified as high risk had died by one year, compared to the survivors $(\mathrm{p}=0.0004)$ (Figure 4).

The vast majority of patients underwent conservatory treatment with unfractionated heparin (Group 1 $82.14 \%$; Group $2-70 \%(\mathrm{p}=0.228), \mathrm{OR}=0.50,95 \% \mathrm{CI}$ : $0.16-1.53$ ). In the deceased group, $30 \%$ of patients had received thrombolytics, whereas in the survivor group, only $15.47 \%$, however, the difference was not significant $(\mathrm{p}=$ $0.2, \mathrm{OR}=2.34,95 \%$ CI: $0.76-7.2$ ).

Multivariate analysis identified the hemodynamic instability (OR $=3.17, \mathrm{p}=0.007$ ), the presence of left $\mathrm{QRS}$ axis deviation $(\mathrm{OR}=4.81, \mathrm{p}=0.001)$, associated pulmonary pathologies $(\mathrm{OR}=3.2, \mathrm{p}=0.02)$ as well as the presence of chronic kidney disease $(\mathrm{OR}=5, \mathrm{p}=0.04)$ as the most powerful predictors of death at one year (Table 4).

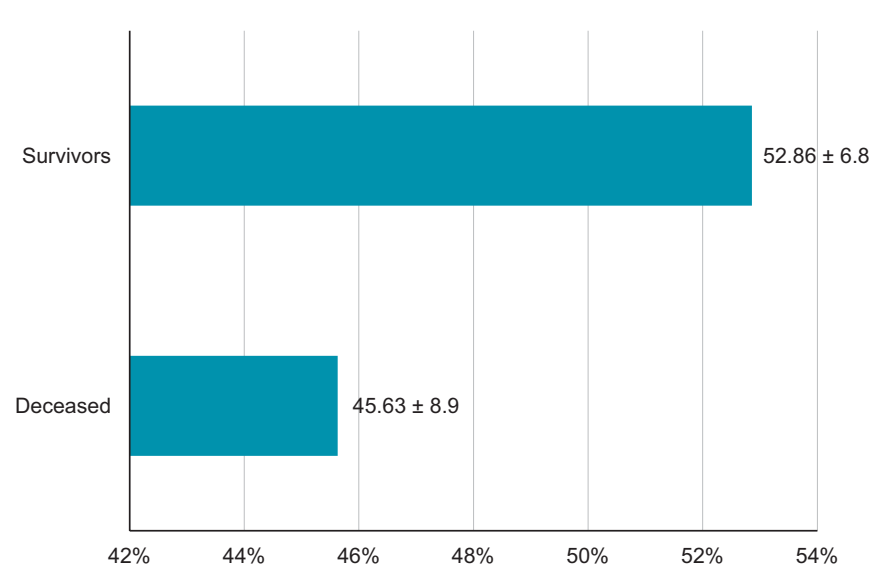

FIGURE 3. Left ventricular ejection fraction measured at baseline

\section{DISCUSSIONS}

The results of the study revealed an overall death rate of $19.23 \%$ at one year following an acute PE, which is lower in comparison to most other results stated in the literature. A study analyzing 572,773 death records in the USA over a twenty-year period, found that $33.9 \%$ of patients had PE as the underlying cause of death. ${ }^{22}$ Furthermore, a European study found that the mortality rates at one year were also higher (37.1\%) compared to the results of the present study. ${ }^{23}$ The main reason for this difference is explained by the fact that the present study enrolled only patients who had survived the acute event of PE. Thus, those cases who died during hospitalization for acute PE or during the first month were excluded from the analysis. Another study that extracted data from the government database based on age- and gender-specific mor-

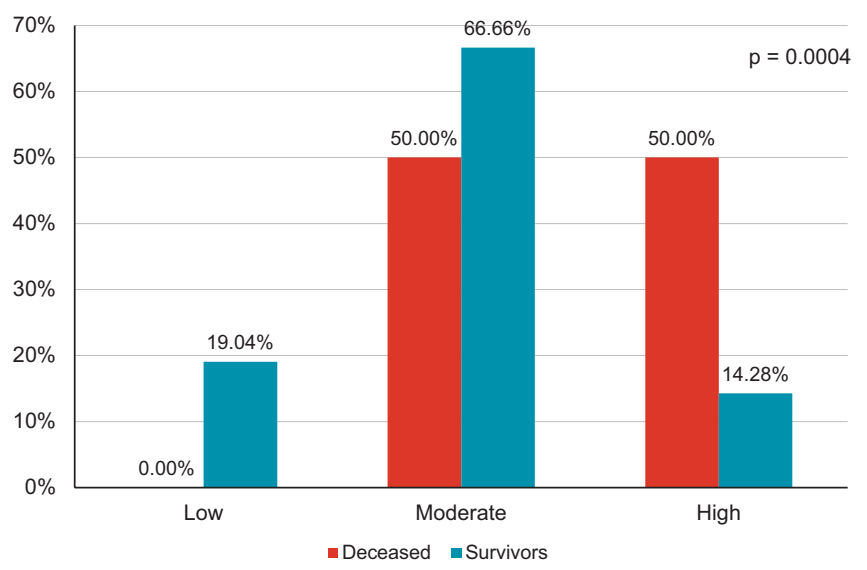

FIGURE 4. Risk categories for PE (Geneva risk score) 
TABLE 4. Multivariate analysis of predictors of mortality in survivors of acute PE

\begin{tabular}{lccc}
\hline & OR & $\mathbf{9 5 \%} \mathbf{~ I I}$ & p value \\
\hline Hemoptysis & 1.421 & $0.13-14.43$ & 0.7 \\
Positive D-dimer & 1.61 & $0.58-4.43$ & 0.3 \\
Tricuspid regurgitation & 0.93 & $0.34-2.5$ & 0.9 \\
Left QRS axis deviation & 4.81 & $1.72-13.49$ & 0.001 \\
RBBB $*$ & 0.75 & $0.19-2.8$ & 0.6 \\
S1Q3T3 pattern on ECG & 0.8 & $0.14-1.05$ & 0.05 \\
Bilateral PE & 0.63 & $0.23-1.74$ & 0.4 \\
Hemodynamic instability ** & 3.17 & $0.99-10.14$ & 0.007 \\
Associated pulmonary pathology & 3.20 & $1.165-8.789$ & 0.02 \\
CKD & 5 & $1.13-22.11$ & 0.04 \\
Arterial Hypertension & 1.105 & $0.38-3.19$ & 1 \\
\hline
\end{tabular}

tality rates concluded that $\mathrm{PE}$ remains a significant cause of death, especially in females and the elderly, ${ }^{24}$ though a Japanese study showed that PE is an important cause of death in young adults. ${ }^{25}$ In the present study, patients who died were significantly older, but there were no differences between the study groups in relation to gender. Stein et al. showed that, despite the fact that obese patients present a higher rate of acute venous thromboembolism, these patients show lower mortality rates compared to normalweight patients. ${ }^{26}$ In the present study patients who died had a higher body weight compared to survivors. Nor was the presence of recurrent $\mathrm{PE}$ associated with a higher mortality rate at one year. This is in line with the results of the study performed by Dentali et al. which observed that previous venous thromboembolism was significantly associated with 1-year survival rates, a possible explanation being the fact that these patients might be subject to an earlier diagnosis and more rapid treatment. ${ }^{23}$

Regarding the hemodynamic parameters, blood pressure values were not different between survivors and the deceased, but a higher peripheral pulse rate was associated with higher mortality. Also, the presence of hemodynamic instability, defined as the presence of shock, inotropic requirement or cardiac arrest during the acute phase of the PE, was associated with a significantly higher death rate for patients who had survived during the onemonth follow-up after an acute PE. Meneveau et al. analyzed the predictors of long-term mortality in patients who had survived the acute phase of PE, and found that the most significant predictors were hemodynamic instability as well as the pulmonary vascular obstruction of more than $70 \%$ of the pulmonary bed. ${ }^{27}$ Furthermore, hemodynamic instability leading to cardiogenic shock and the need for cardiopulmonary resuscitation are all proved parameters for prediction of in-hospital mortality, how- ever their impact on survivors of the acute phase is relatively unknown. ${ }^{28}$

It has been shown that an elevated white blood cell count is associated with a higher risk of thirty-day mortality in PE. ${ }^{29}$ In the present study, except from elevated levels of white cell count, no other biomarkers were associated with higher mortality rates in patients with $\mathrm{PE}$, thus showing that an enhanced inflammatory status during the acute phase is linked with a poorer outcome at one year.

A study investigating the role of ECG in risk stratification for pulmonary embolism demonstrated that the presence of right bundle branch block and the $\mathrm{S}_{103 \mathrm{~T}} 3$ pattern were both associated with right ventricular overload and cardiac injury that occurs secondary to PE..$^{30}$ Interestingly, the present study showed that patients with a left QRS axis deviation had a higher risk of dying during the oneyear follow-up. However, no difference was found between survivors and the deceased regarding the presence of right bundle branch block, negative $\mathrm{T}$ waves in $\mathrm{V} 1-\mathrm{V} 3$ or the presence of the $\mathrm{S} 1 \mathrm{Q} 3 \mathrm{~T} 3$ pattern on the ECG performed at baseline.

In the present study patients with pulmonary pathologies such as chronic obstructive pulmonary disease, asthma, pneumonia or pleural effusion had a higher mortality rate, and it is concluded that an impaired respiratory function can have a negative impact on the prognosis of PE patients. Also, there was a significant association between a negative one-year outcome and the presence of chronic kidney disease. Similarly, Carson et al. followed 399 patients with PE over the course of 1 year, and found that the associated pathologies that were positively correlated with long-term mortality were: presence of cancer $(\mathrm{RR}=3.8 ; \mathrm{CI}: 2.3-6.4)$, left-sided heart failure $(\mathrm{RR}=$ 2.7, CI: 1.5-4.6), and chronic lung disease $(\mathrm{RR}=2.2$; CI: 1.2-4.0), concluding that the long-term outcome of $\mathrm{PE}$ 
mainly depends on the presence and severity of the associated disease. ${ }^{31}$

The presence of malignant conditions has been proved to be a negative predictor of mortality rates in pulmonary embolism..$^{32}$ The RIETE registry that included 35,539 venous thromboembolism patients showed that significantly more patients that presented with PE and an associated form of cancer had died by three months, compared to those without any malignant conditions. ${ }^{33}$ In the present study, the causes of acute PE, including the presence of neoplasm, deep venous thrombosis or the use of oral contraceptives did not show any influence on the overall mortality rates at one year.

Computed tomography pulmonary angiography (CTPA) is the current gold standard technique for the diagnosis of PE. ${ }^{34}$ Ghanima et al. showed that CTPA could also be used for risk assessment and that several CT parameters are correlated with the right ventricular dysfunction as measured by echocardiography, indicating that CT may be considered a new possible prognostic tool for PE patients. ${ }^{35}$ The present study showed no significant differences between survivors and those who died, in regards to thoracic CT angiography. The presence of emboli in both pulmonary arteries was slightly higher in survivors. However, the difference was negligible.

Acute PE has a negative impact on right ventricular (RV) function. RV dysfunction in PE is represented by RV hypokinesis, RV dilation, and signs of pulmonary hypertension..$^{36}$ Analysis of the data of the present study showed that the mean RV diameter was similar between the two groups ( $p=0.9$ ), and there was no difference between the two groups in relation to the presence of tricuspid regurgitation. However, the left ventricular ejection fraction (LVEF) was significantly lower in patients who died at one year, compared to survivors ( $\mathrm{p}<0.05)$.

\section{CONCLUSIONS}

The clinical factors associated with a higher mortality rate at one year in patients who had survived at one month following an acute pulmonary embolism episode were: older age, higher body weight, the presence of associated pulmonary pathologies, chronic kidney disease and left axis deviation upon ECG examination. Also, left ventricular ejection fraction was significantly lower in patients who had died by one year after a PE episode, and hemodynamic instability requiring inotropic support, cardiogenic shock at presentation or cardiac arrest during the acute phase were significantly associated with one-year mortality rates in acute $\mathrm{PE}$.

\section{CONFLICT OF INTEREST}

None declared.

\section{ACKNOWLEDGEMENT}

This research was supported by the Cardio Med Medical Center, project no. CAM/2015/RD/46.

\section{REFERENCES}

1. Heit JA, Silverstein MD, Mohr DN. The epidemiology of venous thromboembolism in the community. Thromb Haemost. 2001;86(1):452-463.

2. Konstantinides SV, Torbicki A, Agnelli G, et al. ESC CommitteeforPracticeGuidelines (CPG). Guidelines on the diagnosis and management of acute pulmonary embolism: the Task Force for the Diagnosis and Management of Acute Pulmonary Embolism of the European Society of Cardiology. Eur Heart J. 2014;35(43):3033-3069. DOI: 10.1093/eurheartj/ ehu283.

3. Nordstrom M, Lindblad B. Autopsy-verified venous thromboembolism within a defined urban population-the city of Malmo, Sweden. APMIS. 1998;106:378-384.

4. Oger E. Incidence of venous thromboembolism: a communitybased study in Western France. EPI-GETBP Study Group. Groupe d'Etude de la Thrombose de Bretagne Occidentale. Thromb Haemost. 2000;83:657-660.

5. McIntyre KM, Sasahara AA. The hemodynamic response to pulmonary embolism in patients without prior cardiopulmonary disease. Am J Cardiol. 1971;28:288-294.

6. Wood KE. Major pulmonary embolism: review of a pathophysiologic approach to the golden hour of hemodynamically significant pulmonary embolism. Chest. 2002;121:877-905.

7. Roy PM, Meyer G, Vielle B, et al. Appropriateness of diagnostic management and outcomes of suspected pulmonary embolism. Ann Intern Med. 2006;144:157-164.

8. Wicki J, Perneger TV, Junod AF, Bounameaux H, Perrier A. Assessing clinical probability of pulmonary embolism in the emergency ward: a simple score. Arch Intern Med. 2001;161:92-97.

9. Le Gal G, Righini M, Roy PM, et al. Prediction of pulmonary embolism in the emergency department: the revised Geneva score. Ann Intern Med. 2006;144:165-171.

10. Grifoni S, Olivotto I, Cecchini P, et al. Short-term clinical outcome of patients with acute pulmonary embolism, normal blood pressure, and echocardiographic right ventricular dysfunction. Circulation. 2000;101:2817-2822.

11. Kasper W, Konstantinides S, Geibel A, Tiede N, Krause T, Just H. Prognostic significance of right ventricular afterload stress detected by echocardiography in patients with a clinically suspected pulmonary embolism. Heart. 1997;77:346-349.

12. Ribeiro A, Lindmarker $\mathrm{P}$, Juhlin-Dannfelt A, Johnsson $\mathrm{H}$, Jorfeldt L. Echocardiography Doppler in pulmonary embolism: right ventricular dysfunction as a predictor of mortality rate. Am Heart J. 1997;134:479-487.

13. Kurzyna M, Torbicki A, Pruszczyk P, et al. Disturbed right ventricular ejection pattern as a new Doppler 
echocardiographic sign of acute pulmonary embolism. Am J Cardiol. 2002;90:507-511.

14. Kucher N, Walpoth N, Wustmann K, Noveanu M, Gertsch M. QR in V1 - an ECG sign associated with right ventricular strain and adverse clinical outcome in pulmonary embolism. Eur Heart J. 2003;24:1113-1119.

15. Petrov DB. Appearance of right bundle branch block in electrocardiograms of patients with pulmonary embolism as a marker for obstruction of the main pulmonary trunk. J Electrocardiol. 2001;34:185-188.

16. Ghaye B, Szapiro D, Mastora I, et al. Peripheral pulmonary arteries: how far in the lung does multi-detector spiral CT allow analysis? Radiology. 2001;219:629-636.

17. Remy-Jardin M, Remy J, Wattinne L, Giraud F. Central pulmonary thromboembolism: diagnosis with spiral volumetric CT with the single-breath-hold techniquecomparison with pulmonary angiography. Radiology. 1991;185:381-387.

18. Patel S, Kazerooni EA, Cascade PN. Pulmonary embolism: optimization of small pulmonary artery visualization at multi-detector row CT. Radiology. 2003;227:455-460.

19. Cavallazzi R, NairA, Vasu T, et al. Natriuretic peptides in acute pulmonary embolism: a systematic review. Intensive Care Med. 2008;34:2147-2156. DOI: 10.1007/s00134-008-1214-5.

20. Coutance GF, Page O, Lo T et al. Prognostic value of natriuretic peptide in acute pulmonary embolism. Crit Care. 2008;12:109. DOI: $10.1186 /$ cc6996

21. Mehmet BK, Güngör B, Göktürk I, et al. Association of Serum Cholesterol Levels with Short-term Mortality in Patients with Acute Pulmonary Embolism. Heart Lung Circ. 2016;25:365370. DOI:10.1016/j.hlc.2015.09.005

22. Horlander KT, Mannino DM, Leeper KV, et al. Pulmonary Embolism Mortality in the United States, 1979-1998: An analysis using multiple-cause mortality data. Arch Intern Med. 2003;163(14):1711-1717.

23. Dentali F, Riva N, Turato S, et al. Pulmonary embolism severity index accurately predicts long-term mortality rate in patients hospitalized for acute pulmonary embolism. J Thromb Haemost. 2013;11:2103-2110. DOI: 10.1111/jth.12420.

24. Shiraev TP, Omari A, Rushworth RL. Trends in pulmonary embolism morbidity and mortality in Australia. Thromb Res. 2013;132(1):19-25. DOI: 10.1016/j.thromres.2013.04.032.

25. Sakuma M, Nakamura M, Takahasi T, et al. Pulmonary
Embolism is an important cause of death in young adults. Circ J. 2007;71:1765-1770.

26. Stein PD, Matta F, Goldman J. Obesity and Pulmonary embolism: The mounting evidence of risk and the mortality paradox. Thromb Res. 2011;128(8):518-523. DOI: 10.1016/j. thromres.2011.10.019.

27. Meneveau N, Pin Ming L, Seronde MF, et al. In-hospital and long-term outcome after sub-massive and massive pulmonary embolism submitted to thrombolytic therapy. Eur Heart J. 2003;24:1447-1454.

28. Kasper W, Konstantinides S, Geibel A, et al. - Management strategies and determinants of outcome in acute major pulmonary embolism: results of a multicenter study. JACC. 1997;30(5):1165-1171.

29. Venetz C, Labarere J, Jimenez D, Aujesky D. White blood cell count and mortality in patients with acute pulmonary embolism. Am J Hematol. 2013;88(8):677-681. DOI: 10.1002/ ajh.23484.

30. Keller K, Beule J, Blazer JO, Dippold W. Right bundle branch block and SIQIII-type patterns for risk stratification in acute pulmonary embolism. J Electrocardiol. 2016;49(4):512-518. DOI: 10.1016/j.jelectrocard.2016.03.020.

31. Carson JL, Kelley MA, Duff A, et al. The clinical course of pulmonary embolism. N Engl J Med. 1992;326:1240-1245.

32. Becattini C, Agnelli G. Acute pulmonary embolism: risk stratification in the emergency department. Intern Emerg Med. 2007;2(2):119-129.

33. Gussoni G, Frasson S, La Regina M, et al. Three-month mortality rate and clinical predictors in patients with venous thromboembolism and cancer. Findings from the RIETE Registry. Thromb Res. 2013;131(1):24-30. DOI: 10.1016/j. thromres.2012.10.007.

34. Van Belle A, Buller HR, Huisman MV, et al. Effectiveness of managing suspected pulmonary embolism using an algorithm combining clinical probability, D-dimer testing, and computed tomography. JAMA. 2006;295(2):172-179.

35. Ghanima W, Sandset PM. Risk stratification of pulmonary embolism by computed tomography. J Intern Med. 2007;262(6):702.

36. Masotti L, Righini M, Vuilleumier N, et al. Prognostic stratification of acute pulmonary embolism: Focus on clinical aspects, imaging, and biomarkers. Vasc Health Risk Manag. 2009;5(4):567-75. 